\title{
Preparation and characterization of poly(lactic-co-glycolic acid) nanoparticles containing TGF- $\beta 1$ and evaluation of in vitro wound healing effect
}

\author{
Aysun ÇELİK SOYSAL ${ }^{1} \mathbb{D}$, Sevinç ŞAHBAZ ${ }^{2} \mathbb{D}$, Timuçin UĞURLU ${ }^{2} \mathbb{D}$, Ali Demir SEZER ${ }^{1 *}$ (D) \\ 1 Department of Pharmaceutical Biotechnology, Faculty of Pharmacy, Marmara University, 34668 Istanbul, Turkey \\ 2 Department of Pharmaceutical Technology, Faculty of Pharmacy, Marmara University, 34668 Istanbul, Turkey \\ * Corresponding author. E-mail: adsezer@marmara.edu.tr; Tel: +90-216-414 2962.
}

Received: 31 January 2020/ Revised: 05 March 2020 / Accepted: 06 March 2020

\begin{abstract}
Wound healing involves many complex mechanisms, and many growth factors are effective in this process. Growth factors are biologically active polypeptides. They perform activities such as cell growth, differentiation, proliferation and migration with molecular cascades by binding to specific receptors. Transforming growth factor stimulates (TGF- $\beta$ ) different cell types in the wound healing process. Poly(lactic-co-glycolic acid) (PLGA) degradation produces lactate that expedites angiogenesis, activates pro-collagen factors. Therewith, we hypothesized to combine the therapeutic effect of the TGF- $\beta 1$ with the positive effect of the drug delivery system including PLGA nanoparticles (TGF$\beta$ - PLGA NP). The burst effect decreases as the polymer concentration increases in PLGA nanoparticles. The inhibitory effect of TGF- $\beta 1$ on keratinocytes was reduced by the improved nanoparticle formulations. It showed a proliferative effect of up to 92.5 per cent on fibroblast cells involved in wound healing. Although TGF- $\beta 1$ has an inhibitory effect on keratinocytes, it induces migration both NIH-3T3 and HaCaT cell lines in the scratch assay.
\end{abstract}

KEYWORDS: Transforming growth factor; PLGA; nanoparticle; wound healing.

\section{INTRODUCTION}

From past to present, the treatment of wounds and burns has an important place in health. Rapid recovery of the wound is a desirable condition to prevent both patient welfare and infection risk [1-3]. Dermal wound healing consists of many cellular mechanisms that progress both systematically and step by step. It starts with hemostasis and inflammation, resulting in extracellular matrix accumulation, angiogenesis, remodelling and scar formation[4]. The wounds are classified according to their appearance, the rate of damage of the skin layers, repair process and cause of injury [5]. Many growth factors and receptors also play a key role. Several studies have been carried out with many cytokines and growth factors in wound healing to accelerate this process [1-3].

One of the growth factors involved in this mechanism is Transforming Growth Factor Beta 1 (TGF- $\beta 1$ ) which is released from platelets, activated macrophages, neutrophils, fibroblasts, keratinocytes, Tlymphocytes and endothelial cells. TGF- $\beta 1$ is a protein with a molecular weight of about $25 \mathrm{kDa}$ and consisting of 112 amino acids monomeric unit of TGF- $\beta$ [6-8]. TGF- $\beta 1$ affects many cell types in the wound area. Fibroblast production and chemotaxis increase the synthesis of ECM components (collagen). It increases protease inhibitor synthesis while decreasing protease expression. It is involved in the chemotaxis and maturation of macrophages. It is stated that it reduces proliferation while increasing keratinocyte maturation [9].

Biocompatible polymeric delivery systems such as PLGA are developed for the distribution, stability and long-term effectiveness of TGF- $\beta 1$ [10-12]. Poly (lactic-co-glycolic acid) (PLGA) is a widely used biodegradable polymer approved by the Food and Drug Administration (FDA) and the European Medicines Agency (EMA). PLGA; polylactic acid (PLA) is formed by polymerization of polyglycolic acid (PGA) monomers in different proportions [11, 12]. PLGA; in addition to its biocompatible, biodegradable, long-term release, it also promotes angiogenesis and activation of procollagen factors in the wound healing area due to its lactate content [4].

How to cite this article: Çelik Soysal A, Şahbaz S, Uğurlu T, Sezer AD. Preparation and characterization of poly(lactic-co-glycolic acid) nanoparticles containing TGF- $\beta 1$ and evaluation of in vitro wound healing effect. J Res Pharm. 2020; 24(2): $277-289$. 
Here we report the evaluation of the characteristics of different formulations of PLGA nanoparticles. We aimed to investigate the efficacy of developed formulations in cell viability and cell proliferation in two different cell lines that take a dominant role in wound healing.

\section{RESULTS AND DISCUSSION}

\subsection{Characterization of PLGA nanoparticles}

A double-emulsion solvent evaporation method was selected for preparation of the NPS due to the hydrophilic nature of TGF- $\beta 1$ protein. Many parameters affect the physicochemical properties of nanoparticles. These include polymer concentration, PVA concentration in the external phase, the concentration of the drug. As the PLGA polymer concentration increases; We tried to examine the size of the nanoparticle, the zeta potential, the polydispersity index, the encapsulation efficiency and the bioadhesive properties.

Five nanoparticle formulations were prepared and indicated in Table 1. The particle size of the filled nanoparticles obtained between 217.4 \pm 3.4 and $289.4 \pm 3.9 \mathrm{~nm}$. Nanoparticles in the 20-200 $\mathrm{nm}$ range are effectively taken up by dendritic cells through endocytosis or pinocytosis and can stimulate a cellular immune response, while microparticles of $0.5-5 \mu \mathrm{m}$ stimulate the phagocytosis or macropinocytosis and humoral response [20]. According to these data, 200-500 nm can be evaluated optimally in terms of the immune system. The nanoparticle size range in our study was also found to be compatible with these data. In formulations containing $1 \%, 2 \%, 3 \%, 4 \%$ and $5 \%$ PLGA concentrations, filled nanoparticles were larger at size than empty ones and showed statistical significance $(\mathrm{p}<0.05)$. Several studies have reported an increase in nanoparticle size as PLGA concentration increases [21-23]. In addition to these views, it has been suggested that as the PLGA polymer concentration increases, particle size may decrease in the study of Mensah et al. [24]. In our study, no linear increase in nanoparticle size was observed due to polymer concentration.

The zeta potential of the nanoparticles is between $-29.6 \pm 2.1$ and $-26.8 \pm 0.9$. There is no statistical significance between the zeta potential of filled nanoparticle formulations (B, D, F, H, J). PLGA concentration did not significantly differ on zeta potential $(\mathrm{p}>0.05)$ [25].

Table 1. Formulation of PLGA nanoparticles and characterization analysis including size, zeta potential, polydispersity index, encapsulation efficiency and bioadhesion study.

\begin{tabular}{|c|c|c|c|c|c|c|c|c|}
\hline 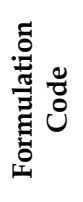 & 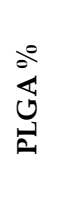 & $\sum_{a}^{0}$ & $\begin{array}{l}\overline{0} \\
\frac{1}{1} \\
0\end{array}$ & 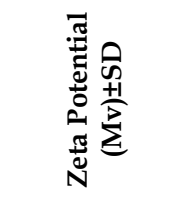 & क ज芯 & 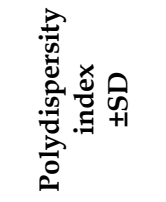 & 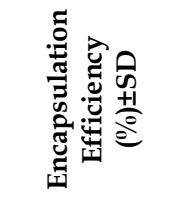 & 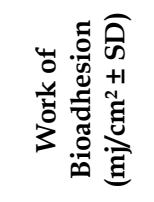 \\
\hline $\mathbf{A}$ & 1 & 1 & - & $-19.86 \pm 0.40$ & $240.66 \pm 4.88$ & $0.329 \pm 0.03$ & - & - \\
\hline B & 1 & 1 & + & $-26.83 \pm 0.94$ & $289.40 \pm 3.90$ & $0.323 \pm 0.01$ & $98.85 \pm 0.25$ & $0.11 \pm 0.13$ \\
\hline $\mathrm{C}$ & 2 & 1 & - & $-26.68 \pm 1.64$ & $195.63 \pm 3.74$ & $0.281 \pm 0.04$ & - & - \\
\hline $\bar{D}$ & 2 & 1 & + & $-26.98 \pm 1.30$ & $217.43 \pm 3.40$ & $0.286 \pm 0.04$ & $99.54 \pm 0.11$ & $0.19 \pm 0.03$ \\
\hline $\mathrm{E}$ & 3 & 1 & - & $-22.85 \pm 3.50$ & $215.83 \pm 2.82$ & $0.328 \pm 0.01$ & - & - \\
\hline $\mathbf{F}$ & 3 & 1 & + & $-27.17 \pm 3.25$ & $274.76 \pm 1.50$ & $0.317 \pm 0.01$ & $99.52 \pm 0.12$ & $0.12 \pm 0.08$ \\
\hline $\mathrm{G}$ & 4 & 1 & - & $-24.70 \pm 0.63$ & $197.16 \pm 16.31$ & $0.346 \pm 0.02$ & - & - \\
\hline $\mathbf{H}$ & 4 & 1 & + & $-29.64 \pm 2.09$ & $236.06 \pm 4.05$ & $0.331 \pm 0.03$ & $99.64 \pm 0.03$ & $0.17 \pm 0.02$ \\
\hline I & 5 & 1 & - & $-28.08 \pm 3.15$ & $163.56 \pm 13.92$ & $0.316 \pm 0.07$ & - & - \\
\hline $\mathbf{J}$ & 5 & 1 & + & $-28.52 \pm 4.52$ & $258.00 \pm 16.36$ & $0.298 \pm 0.02$ & $99.88 \pm 0.04$ & $0.12 \pm 0.03$ \\
\hline
\end{tabular}


The polydispersity index (PDI) of the nanoparticles is in a narrow range and no significant difference is observed between the formulations. It is in the range of 0.281-0.346. Polydispersity index values showed that the nanoparticles were homogeneous and the method used was reproducible and stable [15].

The encapsulation efficiency of the nanoparticles was determined by calculating the amount of nonencapsulated TGF-B1 protein in their supernatants by ELISA kit and high rates were obtained (Table 1). All nanoparticles showed high encapsulation efficiency. This may be due to the use of a small amount of TGF-B1, such as $1 \mu \mathrm{g}$, during the preparation of the nanoparticles. The formulation showing maximum encapsulation efficiency is group J. $99.8 \%$ showed a near hundred per cent efficiency. Generally, BSA is used to stabilize growth factors in peptide-protein structure and TGF- $\beta 1$ was prepared in $0.1 \%$ BSA in our study. PLGA was selected with (L: G / 50: 50) 503H acid terminal. So; The carboxylic acid chain of PLGA enhances the interaction with the protein, allowing the protein to enter the polymer nanoparticle better and as a result is thought to provide high encapsulation efficiency $[13,26]$. The encapsulation efficiency of PLGA nanoparticles is between $98.8 \pm 0.2 \%$ and $99.8 \pm 0.04 \%$, resulting in a relatively high rate (Table 1). Encapsulation efficiency increases with increasing polymer concentration [22]. Formulation B has the statistically lowest encapsulation efficiency $(\mathrm{P}<0.05)$. The encapsulation efficiency for other formulations was not statistically significant as it was close to each other. These encapsulation activities are quite high compared to other delivery systems (such as micro / nano particles with $25-50 \%$ ratios) $[25,27,28]$.
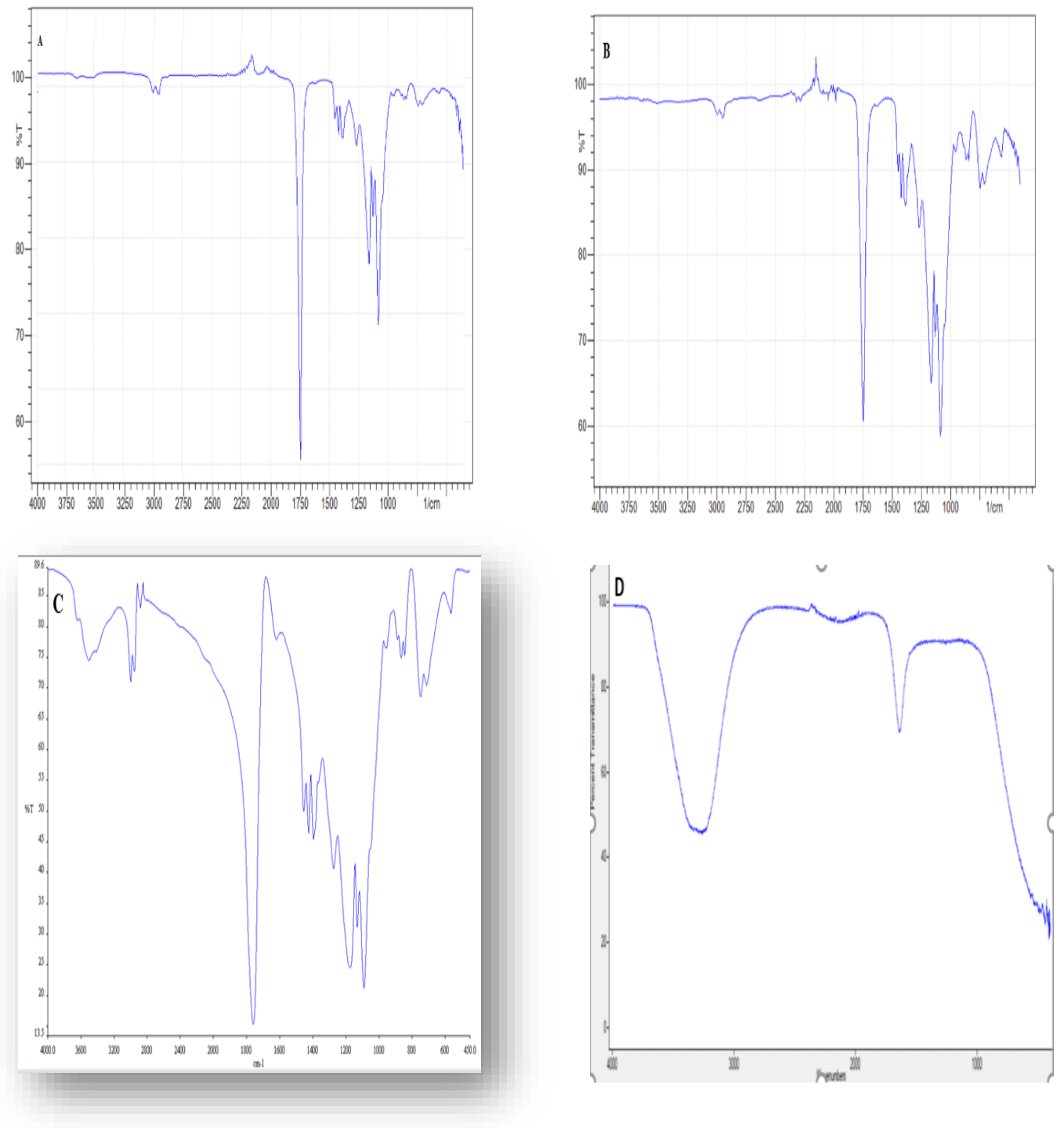

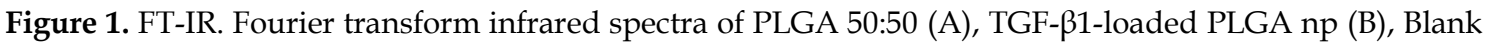
$n p(C)$, TGF- $\beta 1$ protein (D). 
FTIR study was carried out to confirm the compatibility between the polymer PLGA and drug (TGF- $\beta 1$ protein) and nanoparticle formulation were shown in Figure 1. In Figure 1A, functional groups such as carbonyl $-\mathrm{C}=\mathrm{O}$ stretching $\left(1780-1720 \mathrm{~cm}^{-1}\right), \mathrm{C}-\mathrm{O}$ stretching $\left(1310-1160 \mathrm{~cm}^{-1}\right),-\mathrm{CH}\left(2990-2830 \mathrm{~cm}^{-1}\right)$ showed the PLGA polymer structure. In Figure 1B, infrared spectroscopy was used to study the interactions between the drug and the polymers. The PLGA 50:50 nanoparticles showed peaks such as $\mathrm{OH}$ stretching (3560-3450 $\left.\mathrm{cm}^{-1}\right)$, $-\mathrm{CH}\left(3000-2855 \mathrm{~cm}^{-1}\right)$, carbonyl $-\mathrm{C}=\mathrm{O}$ stretching $\left(1780-1720 \mathrm{~cm}^{-1}\right)$ and C-O stretching $\left(1310-1160 \mathrm{~cm}^{-1}\right)$. The PLGA nanoparticle formulation, which has similar structures to $1 \mathrm{~A}$, has been shown to contain specific functional groups. As a result of the study, it is seen that the protein is encapsulated into the nanoparticle. The blank nanoparticles in Figure 1C, observed structure peaks similar to filled nanoparticles, although slight shifts were observed in the peaks. In Figure 1D, In terms of amino acids, which are the basic structure of the protein, the large peak amine-derived $\mathrm{N}-\mathrm{H}$ at $3262 \mathrm{~cm}^{-1}$ and the $\mathrm{O}-\mathrm{H}$ peak from the carboxyl group were evaluated. $\mathrm{C}$ $=\mathrm{N}$ vibrations seen in compact structure as a result of weak bond protein folding at $2140 \mathrm{~cm}^{-1}$ are included. $\mathrm{C}=\mathrm{O}$ carbonyl stretching can be seen in $1636 \mathrm{~cm}^{-1}$ [29].

The morphological properties and the size of the NPs were characterized by SEM. PLGA NPs were found to have a smooth and spherical surface morphology (Figure 2). Although there is a heterogeneous appearance in the particle system as a result of sem imaging analysis, most particles are nano-sized and nanoparticles were found to be compatible with size measurements using Zetasizer.

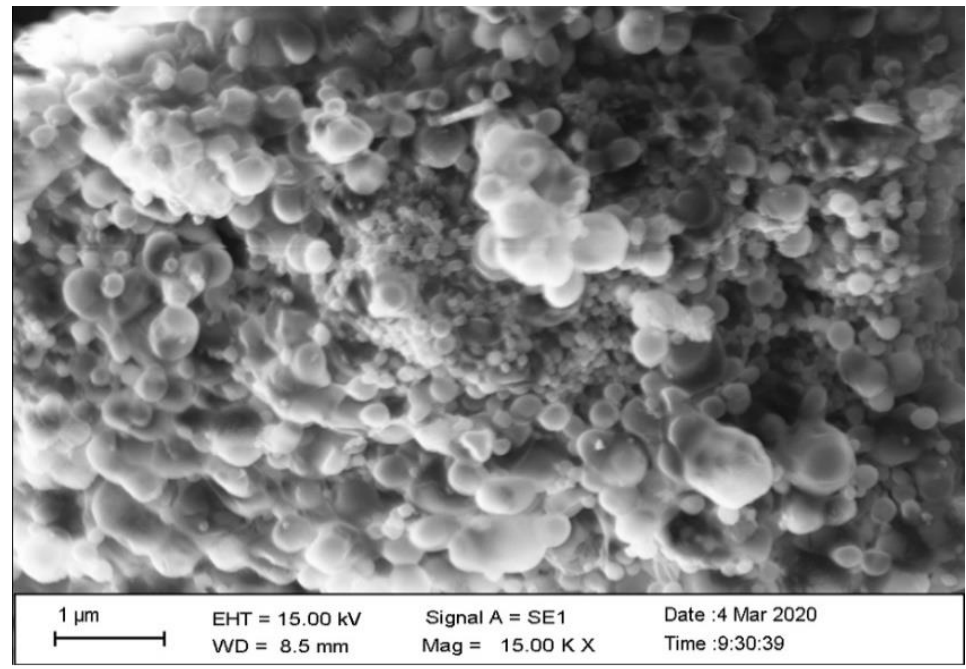

Figure 2. Scanning electron micrograph of TGF- $\beta 1$-loaded PLGA NPs.

DSC studies were carried out to determine drug status in developed nanoparticles and drug-polymer interaction during the production of nanoparticles. In Figure 3, shows DSC thermograms of blank PLGA nps and TGF- $\beta 1$ loaded nps. The endothermic peak at about $52^{\circ} \mathrm{C}$ is the melting point of PLGA. This peak was observed in both empty and filled nanoparticles. There was no change in the physical characteristics of TGF$\beta 1$ containing nanoparticles formulation. Accordingly, TGF- $\beta 1$ protein is compatible with the polymer [30].

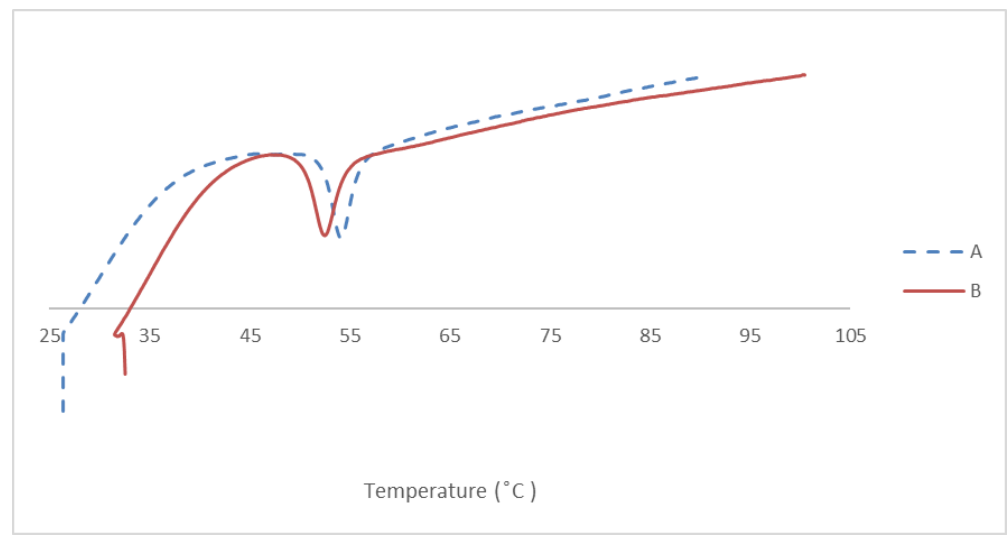

Figure 3. DSC thermograms TGF- $\beta 1$ - loaded PLGA nanoparticles (A), blank nanoparticles (B). 


\subsection{In vitro release studies of PLGA nanoparticles}

The release behaviour of the drug from the polymer matrix was realized as a biphasic system. It was initially characterized by a burst effect, followed by a slower sustained release. The release was determined using ELISA. This method is highly specific and sensitive to identify the protein of interest. Drug release amounts differed according to PLGA concentration. As the PLGA concentration increased, the burst effect decreased and a slower release occurred. Drug release of B, D, F, H and J formulations showed at the end of 30 days $35.1 \%, 25.2 \%, 24.3 \%, 19.06 \%$, respectively as depicted in Figure 4 . The lowest $(8.72 \%)$ burst effect was observed at $5 \%$ PLGA concentration and the highest rate $(20.88 \%)$ was observed at $1 \%$ in Figure 4 . The initial burst drug release may be due to the presence of the surface drug on the surface area of the NPs. Also, the presence of the carboxylic acid group at the terminus of the PLGA polymer allows for better interaction with the protein and stabilizer BSA. As a result, a controlled release was observed with increased encapsulation and reduced burst effect [26].

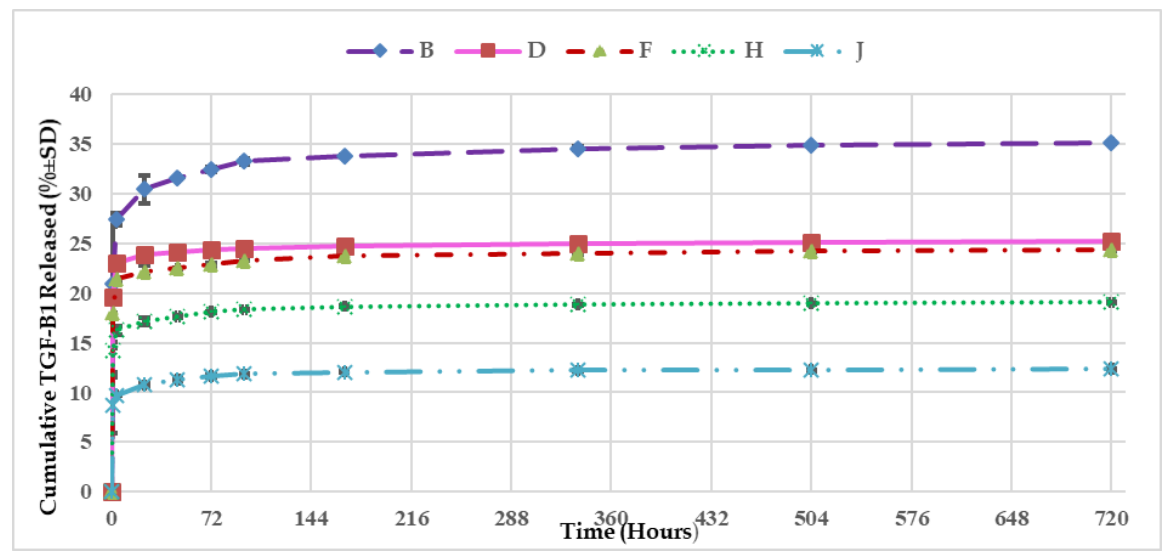

Figure 4. TGF- $\beta 1$ release profiles from the PLGA nanoparticles. The error bars represent the standard deviations with $\mathrm{n}=3$ for each one. (PBS buffer, $\mathrm{pH} 7.4,37^{\circ} \mathrm{C}$ ).

\subsection{In vitro bioadhesion studies of PLGA nanoparticles}

Bioadhesion values of the microspheres varied between 0.113 and $0.198 \mathrm{~mJ} / \mathrm{cm}^{2}$ (Table 1). There was no significant difference in the bioadhesion properties between nanoparticle formulations containing different PLGA concentrations ( $\mathrm{p}>0.05)$. The bioadhesion study of all nanoparticles is shown graphically in Figure 5. In the microparticle study carried out by Sezer et al. with chitosan and fucoidan, the triple-level of chitosan increased by 2.5 times in bioadhesion values, from 0.081 to $0.191 \mathrm{~mJ} / \mathrm{cm}^{2}$ [16]. It is suggested that chitosan has an adhesive structure as a polymer. In our study, the bioadhesion values of PLGA nanoparticles are in a similar range without chitosan. Therefore, PLGA nanoparticles are thought to exhibit a bioadhesiveness that cannot be ignored. This also; it provides an advantage in application to the injured area [16,17].

\subsection{Cell culture studies}

\subsubsection{Cell viability assay (MTT assay)}

In the MTT study, NIH-3T3 fibroblast cell line, which is one of the most common cells in wound healing, was used. In Figure 6A, it has been shown that both empty and filled nanoparticles are not cytotoxic and cause significant increases in cell viability. All nanoparticles significantly increased cell viability compared to both control and TGF- $\beta 1$ ( $p<0.05)$. Although there was no linear increase in cell viability with the increase in PLGA concentration, especially the empty nanoparticles E (3\%), G (4\%) and filled ones F (3\%), H (4\%) showed the best viability increase. The F-coded nanoparticle achieved a $196.81 \%$ maximum cell viability increase in the fibroblast cell line. This increase in NPs may be due to PLGA-induced lactic acid induction. As reported by Chereddy et al., high cell viability increases due to filled nps result from the combined effect of TGF- $\beta 1$ and lactic acid induction. This delivery system created a combined effect. The findings that we have achieved are supported by Chereddy and his colleagues [4]. Reduction in cell viability was also observed in the forms after $3 \%$ Plga concentration in the formulations. In general, the increase in cell viability of the formulations compared to the TGF- $\beta 1$ protein indicates that the formulations provided protein stability. It is stated that the 
carrier system protects the protein against proteases and nuclease in the cell environment and provides its stability. Our study supports this [31].

In MTT assay for HaCaT cell line, none of the PLGA nanoparticle formulations are cytotoxic (Figure $6 \mathrm{~B})$. It was observed that the empty nanoparticles had higher cell viability statistically compared to those filled $(p<0.05)$. This result we obtained was in line with the Brdu cell proliferation study. Steven et al. TGF- $\beta 1$ is reported to reduce the proliferation of keratinocytes in wound healing [9]. The result of our study is similar. In the study, no difference was observed between nanoparticles due to PLGA concentration. Inhibition effect of TGF- $\beta 1$ on keratinocytes is known compared to control. Among the nanoparticle formulations developed, $\mathrm{F}$ (with a rate of $98.01 \%$ ) has been demonstrated in vitro to increase the viability by reducing inhibition of keratinocytes involved in the wound healing process $(\mathrm{p}<0.05)[6-9]$.

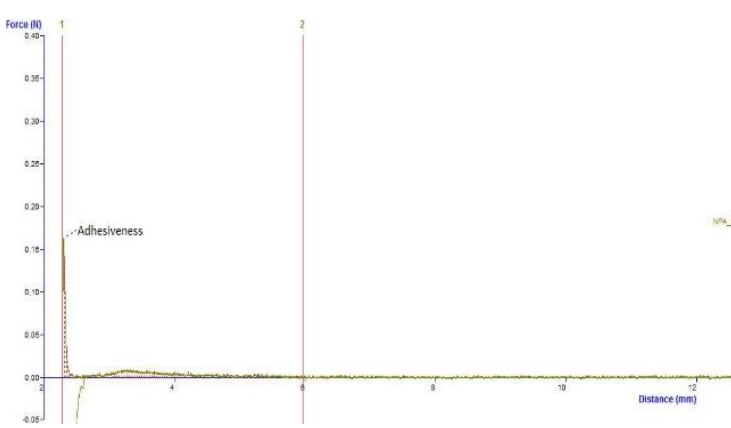

A)B

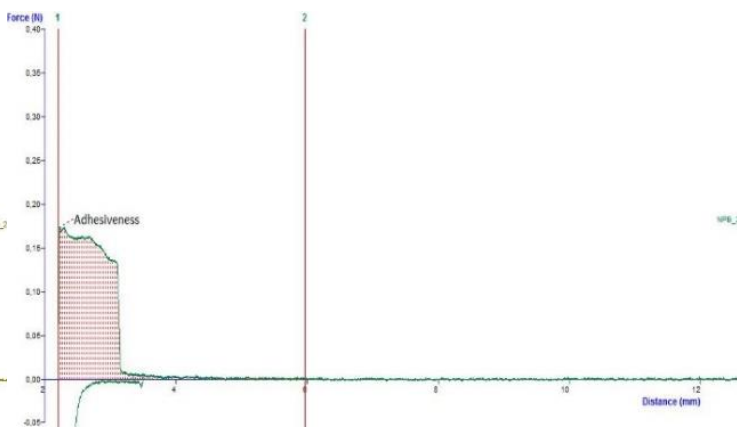

B)D

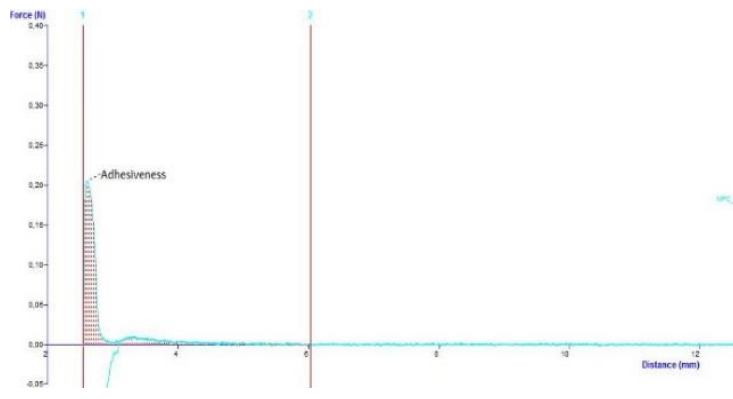

C) $F$

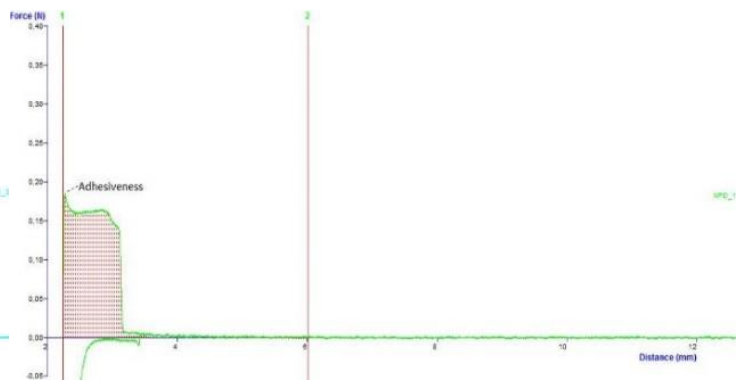

D)H

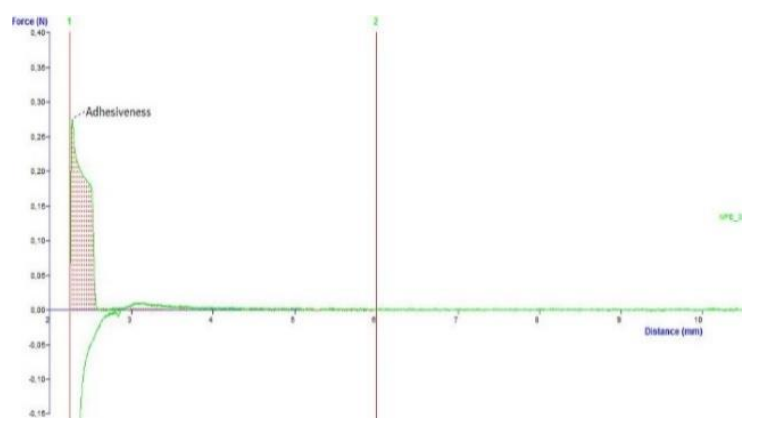

E) J

Figure 5. Work of bioadhesion graphs of the nanoparticles with B, D, F, H and J formulation codes. $(n=3)$. Bioadhesion studies were performed on fresh chicken back skin using 110 perspex probe ( $\mathrm{R}: 10 \mathrm{~mm}$, contact area: $0.785 \mathrm{~cm}^{2}$ ). [ A)B, B)D, C)F, D)H, E)J ].

\subsubsection{BrdU cell proliferation assay}

In the BrdU assay, the statistically significant formulations between empty and filled nanoparticles were $2 \%(\mathrm{C}-\mathrm{D}), 3 \%(\mathrm{E}-\mathrm{F}), 4 \%(\mathrm{G}-\mathrm{H})(\mathrm{p}<0.05)$. While $\mathrm{C}, \mathrm{D}, \mathrm{E}, \mathrm{F}, \mathrm{H}$-coded nps increase cell proliferation compared to control; compared to TGF- $\beta 1, D, E, F, H$ coded NPS significantly increased cell proliferation $(p<0.05)$. In the in vitro study, the highest proliferation effect was observed in the $3 \%$ " F " nanoparticle for fibroblast cells, with 
an increase of $92.5 \%$. Although TGF- $\beta 1$ protein increases fibroblast proliferation by $7 \%$ compared to control, it is not statistically significant $(\mathrm{p}>0.05)$. The formulations developed provide more proliferation than TGF- $\beta 1$ protein delivered to the cell alone, indicating that the carrier system provides effective protein stability [31]. In our study; due to the increased PLGA concentration, formulations with concentrations greater than 3\% showed a decrease in fibroblast cell proliferation, as supported by the MTT study (Figure 7A).

In Figure 7B, nanoparticles containing TGF- $\beta 1$ showed a lower proliferative effect compared to empty ones due to the protein's keratinocyte inhibition effect $(p<0.05)$. Formulations $\mathrm{F}, \mathrm{H}$ and J are thought to support the proliferation of keratinocytes by reducing the cell proliferative inhibition effect of TGF- $\beta 1$ alone. In our MTT study for HaCaT cell line, it supports the cell proliferation study. Especially the F ( $3 \%$ ) coded nanoparticle is the common effective formulation of both studies [6-9].
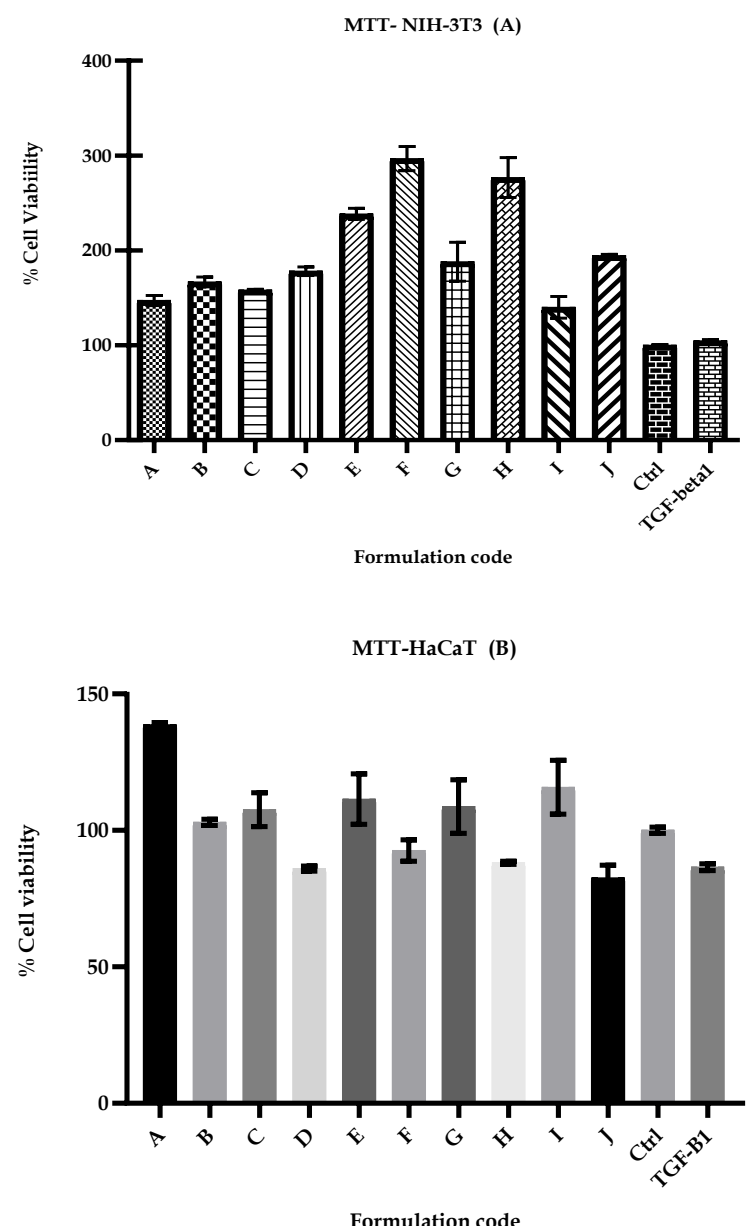

Figure 6. MTT cell viability results of fibroblast (A) and keratinocyte (B) cell lines $(\mathrm{n}=3)$. Control groups include DMEM and fibroblast (A)/ DMEM and keratinocyte (B).

\subsubsection{In vitro wound-healing assay ( Scratch assay)}

Using a scratch test, we aimed to investigate the combined effect of empty and filled PLGA nanoparticles as drug delivery systems, the ability to accelerate the closure of a single-celled and artificially injured wound. As a result of the characterization studies, F coded nanoparticle was selected. After a 48-hour repair period at $37^{\circ} \mathrm{C}, \mathrm{HaCaT}$ and $\mathrm{NIH}-3 \mathrm{~T} 3$ cells proliferated more effectively and migrated to the damaged area in the presence of improved formulations than media only and medium containing TGF- $\beta 1$ (Figure 8).

In the NIH-3T3 fibroblast cell line showed a proliferative effect with E-code nanoparticle lactate induction, increasing the cell population in the damaged area. F, the filled nanoparticle, showed the expected combine effect and formed the best wound healing response.

The HaCat cell line had no proliferative effect on E-encoded nanoparticle keratinocytes. In addition, it is thought that it does not contribute to migration since it does not contain TGF- $\beta 1$. F has been observed to 
provide maximum cell migration. Within both cell lines; TGF- $\beta 1$ protein alone achieved less migration compared to the F-code nanoparticle $[4,14,19]$.

BrdU- NIH-3T3 (A)

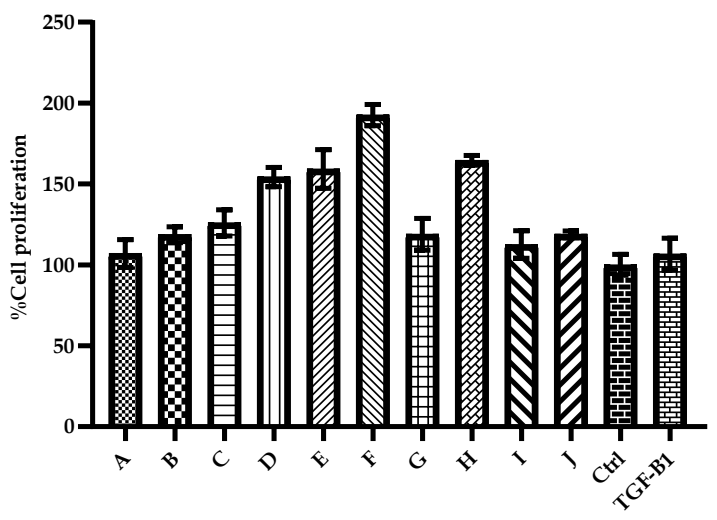

Formulation code

BrdU-HaCaT (B)

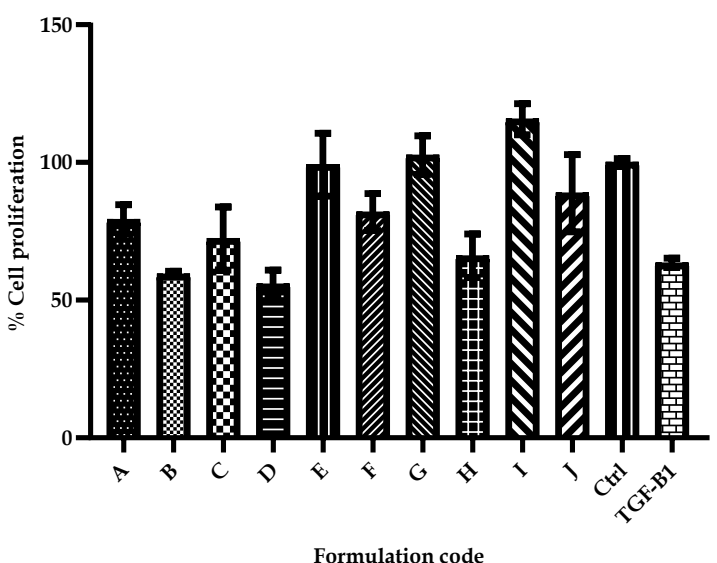

Figure 7. BrdU cell proliferation results of fibroblast $(A)$ and keratinocyte $(B)$ cell lines $(n=3)$. Control groups include DMEM and fibroblast (A)/ DMEM and keratinocyte (B).

\section{CONCLUSION}

The main cells involved in the wound healing process are fibroblasts and keratinocytes. The combined effect of the PLGA nanoparticles and TGF- $\beta 1$ we developed was achieved after results that accelerated wound closure in vitro. This effect was mostly observed in F nanoparticles with a concentration of $3 \%$ PLGA. In addition, in parallel with in vitro studies, our active ingredient protein (TGF- $\beta 1$ ) has been shown to improve stability by increasing stability. It is promising that the drug delivery systems developed are biocompatible for the wound healing process, both alone and in combination with growth factor TGF- $\beta 1$.

\section{MATERIALS AND METHODS}

\subsection{Materials}

Recombinant human TGF- $\beta 1$ Peprotech, USA; TGF- $\beta 1$ ELISA kit Enzo Life Sciences, USA; Poly(vinyl alcohol) (PVA, 88\% hydrolized, Mw 25,000) Polysciences Inc, Warrington, PA; Poly (L,D-lactic-co-glycolic acid) (PLGA, RG503H), Boehringer Ingelheim, Germany; dichloromethane (DCM) Merck, Germany; Bovine Serum Albumin (BSA) BioShop, Canada Inc. Were obtained from these companies. 3-(4,5-dimethylthiazol-2yl)-2,5-diphenyltetrazolium bromide (MTT) Roche, Switzerland; BrdU (5-Bromo-2'-deoxyuridine) Cell Proliferation Assay Merck Millipore, USA; NIH 3T3 ( ATCC-CRL-1658) and HaCaT( ATCC-PCS 200-011 were used in our studies. All materials used are in analytical grade. 


\subsection{Preparation of PLGA nanoparticles}

PLGA nanoparticles (np) were prepared by a double-emulsion (water-in-oil-in-water) solvent evaporation technique. Different amount of PLGA dissolved in $2 \mathrm{ml}$ DCM. $1 \mu \mathrm{g} / 10 \mu \mathrm{l}$ TGF- $\beta 1$ with BSA \%0.1 was added in it and homogenized (w/o). After that, the mixture was poured into $50 \mathrm{ml}$ PVA $1 \%$ and homogenized $(\mathrm{w} / \mathrm{o} / \mathrm{w})$. The mixture was stirred using a magnetic stirrer to remove the excess amount of DCM $[13,14]$. The nanoparticles were separated by centrifugation at $12,000 \mathrm{rpm}$ for $20 \mathrm{~min}$. Then, the NPs were washed three times with deionized water and lyophilized (Lyovac GT 2E, Steris, Germany). PLGA nanoparticles are shown in Table 1.

\subsection{Characterization of PLGA nanoparticles}

\subsubsection{Size, zeta potential and PDI of PLGA nanoparticles}

The zeta potential, size and polydispersity index (PDI) measurements of nanoparticles were determined in a deionized water solution, $25^{\circ} \mathrm{C}$ by using Zetasizer nano zs (Malvern Instruments, UK). All measurements were performed in triplicates.

\subsubsection{Encapsulation efficiency of PLGA nanoparticles}

The encapsulation efficiency is determined by calculating the amount of the non-encapsulated protein in the supernatant. Encapsulation efficiency was detected using an enzyme-linked immunoassay kit (TGF- $\beta 1$ ELISA kit) [15]. The encapsulation efficiency was calculated using the following equation.

Encapsulation efficiency $(\%)=\frac{\text { Amount of drug in a definite mass of the prepared particle }(\mathrm{mg}) \times 100}{\text { Theoretical amount of drug in the same mass }(\mathrm{mg})}$

\subsubsection{Fourier transform infrared spectroscopy}

IR spectrum of TGF- $\beta 1$ protein, PLGA polymer and PLGA nanoparticles were obtained. All formulations were freeze-dried. FT-IR spectra in the absorbance mode were recorded using FT-IR spectrometer (Thermo). Various peaks in the IR spectrum were interpreted for the presence of different groups.

\subsubsection{Scanning electron microscopy}

The morphology of the nanoparticles was observed by scanning electron microscopy (SEM) (Carl ZEISS/ EVO 40/Germany). Some nanoparticles were placed on a metallic surface, then coated with a goldpalladium layer. Observations were made at $10 \mathrm{kV}$.

\subsubsection{Differential scanning colourimetric (DSC) analysis of PLGA nanoparticles}

Differential Scanning Calorimetry (Setaram 131; Setaram Instrumentation) was performed to characterize the physical state of TGF- $\beta 1$ in the nanoparticle. About $6 \mathrm{mg}$ of sample was weighed, crimped into an aluminium pan and analyzed at a scanning temperature range from 25 to $100^{\circ} \mathrm{C}$ at a heating rate of $5^{\circ} \mathrm{C} / \min [15]$.

\subsection{In vitro release studies of PLGA nanoparticles}

The TGF- $\beta 1$ release was performed for 30 days in a $37^{\circ} \mathrm{C}$ water bath. PLGA nanoparticle-containing 10 ng TGF- $\beta 1$ was weighed and incubated in $1 \mathrm{ml}$ PBS (pH: 7.4) buffer. At the sampling times, the samples were centrifuged at $14000 \mathrm{rpm}$ for 15 minutes, the supernatant was stored at $-20^{\circ} \mathrm{C}$ and fresh PBS was added and maintained until the following time. Amounts of rhTGF- $\beta 1$ released from nanoparticles were quantified using the ELISA kit (Enzo Life Sciences, USA). All samples were performed 3 times and standard deviations were indicated.

\subsection{In vitro bioadhesion studies of PLGA nanoparticles}

The bioadhesion of the nanoparticles was measured by described the method in articles 16 and 17 . Measurements were determined using TA-XT Plus Texture Analyzer (Stable Micro Systems, UK), with p10 perspex probe ( R:10 mm, contact area: $0.785 \mathrm{~cm}^{2}$ ) and $5 \mathrm{~kg}$ load cell. Fresh chicken back skin was cleaned from fat and debris and used as a tissue model (Ethical approval was obtained). The excised chicken skins were kept at $37^{\circ} \mathrm{C}$ before the test. Each measurement was made with fresh chicken skins [16, 17]. The surface 
of the skin placed on the probe was washed with distilled water before starting the test. $5 \mathrm{mg}$ of nanoparticle was weighed and attached to the bottom surface of the probe with double-sided adhesive tape. The nanoparticle-coated lower surface of the probe was applied to the tissue surface with a constant speed of 1 $\mathrm{mm} / \mathrm{s}$ and $1.0 \mathrm{~N}$ constant force. After 2 minutes of contact time, the probe was removed in the vertical direction at the same constant speed. Data collection and calculation were performed by using the Texture Exponent 4.0.4.0 software package of the instrument. The area under the curve (AUC) was calculated from the forcedistance plot as the work of bioadhesion using Texture Exponent 4.0.4.0 software package of the instrument [16]. Each measurement was performed in triplicate.
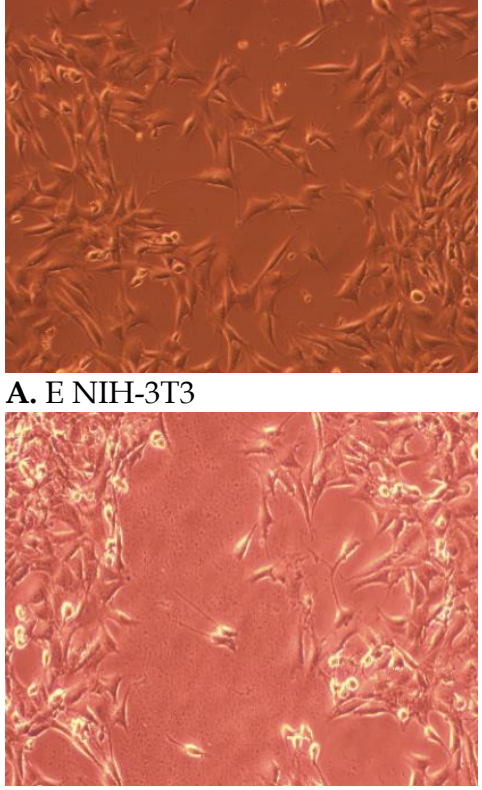

D. Control NIH-3T3

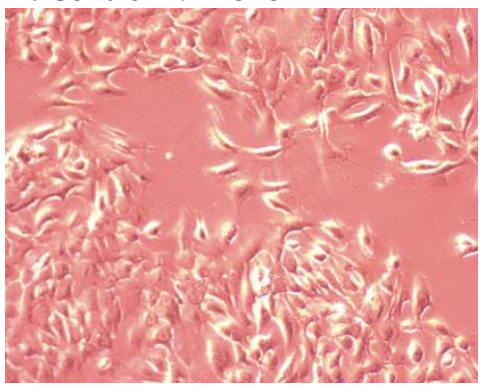

G. TGF- $\beta 1 \mathrm{HaCaT}$

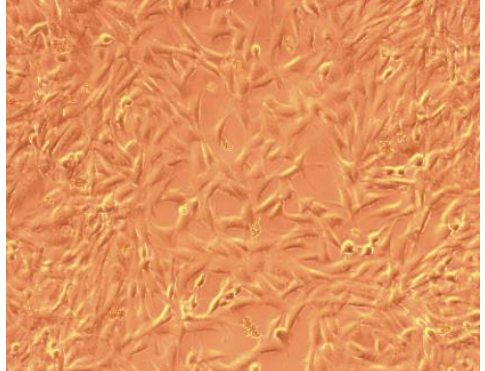

B. F NIH-3T3

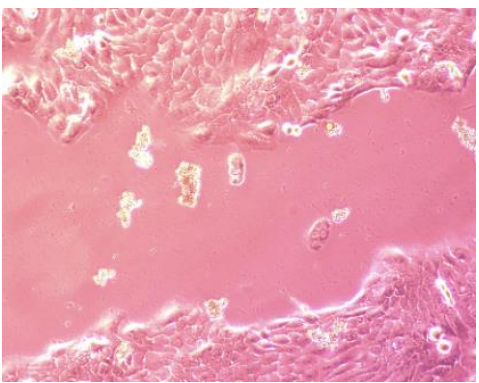

E. E HaCaT

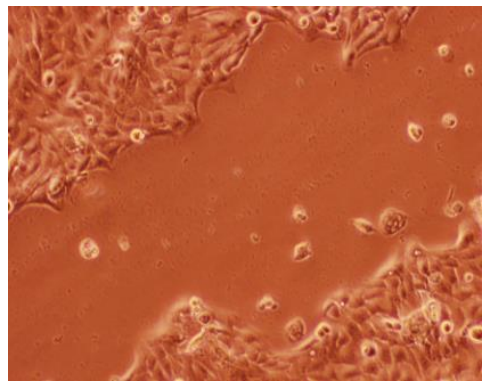

H. Control HaCaT

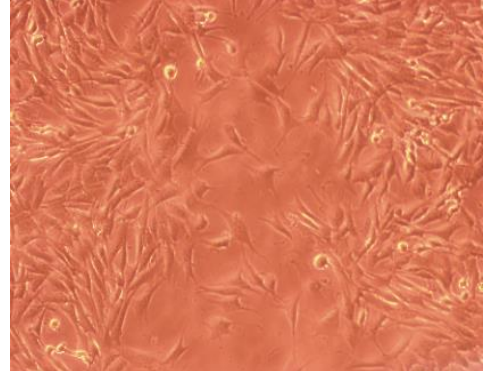

C. TGF- $\beta 1$ NIH-3T3

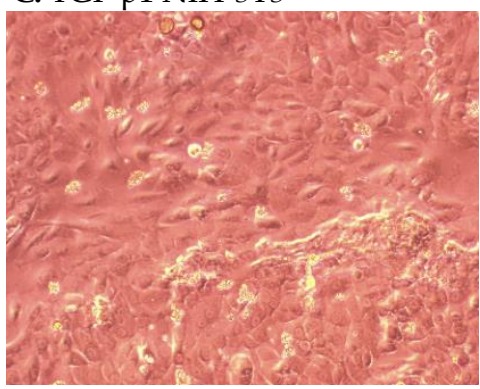

F. F HaCaT

Figure 8. Scratch test. HaCaT and NIH-3T3 cells were seeded in six well plates and reached 70-80\% of the cell population. A pipette tip was scratched and a photo was taken immediately. Cells were kept at $37^{\circ} \mathrm{C}$ for 48 hours, allowing repair of the damage and repeating the photograph. TGF-B1 ( $2.5 \mathrm{ng} / 500 \mu \mathrm{l})$ was applied as a positive control. The experiment was repeated twice and similar results were obtained.

\subsection{Cell culture studies}

\subsubsection{Cell viability assay (MTT assay)}

Cytotoxicity of nanoparticles was measured by the MTT (3-(4,5-Dimethylthiazol-2-yl)-2,5diphenyltetrazolium bromide) assay, using NIH-3T3 ( ATCC-CRL-1658) and HaCaT( ATCC-PCS 200-011) cells. Cells were seeded at $1 \times 10^{4}$ cells/well in 96-well plates (TPP, Trasadingen, Germany) with $100 \mu \mathrm{L}$ complete medium (DMEM containing 10\% FBS) and incubated overnight. Nanoparticles were weighed to contain $2.5 \mathrm{ng}$ of TGF- $\beta 1$ protein and were suspended with DMEM medium. TGF- $\beta 1$ ( $2.5 \mathrm{ng} / 500 \mu \mathrm{l})$ was applied as a positive control. After treatment, the cells were incubated for $24 \mathrm{~h}$. After incubation, $10 \mu \mathrm{l}$ of MTT solution $(5 \mathrm{mg} / \mathrm{ml})$ was added to each well and the cells were incubated for $12 \mathrm{~h}\left(37^{\circ} \mathrm{C}, 5 \% \mathrm{CO}_{2}\right)$. The formazan crystals, formed by live cells, were incubated for 24 hours to dissolve all. Then it was measured 
spectrophotometrically at their absorbance at 550 and $690 \mathrm{~nm}$ using a microplate ELISA reader (Epoch Biotech USA 13121287. Cell viability was expressed as percentages compared to control groups $[18,19]$.

\subsubsection{BrdU cell proliferation assay}

The proliferation of NIH 3T3 and HaCaT cells was determined using a colourimetric immune assay based on the measurement of BrdU, which was incorporated during DNA synthesis. The BrdU assay was carried out according to the manufacturer's instructions. In the BrdU test, cell seeding, the addition of formulations and incubation period were performed the same as in the MTT test. The more BrdU attaches in place of the Thymine nucleotide in the DNA of proliferating cells, the bluer it is the colour of positive cells as a result of DNA synthesis. The reaction was stopped by pipetting $100 \mu \mathrm{L} /$ well of the acid Stop solution provided into each well. The colour of positive wells changed from blue to bright yellow. After then absorbance of plate was calculated by using an ELISA reader (Epoch Biotech 13121287 USA) set at a dualwavelength of $450 / 550 \mathrm{~nm}$.

\subsubsection{In vitro wound healing assay ( Scratch assay)}

For the in vitro wound healing assay, optimized formulation, F, nanoparticle and its empty form, E, were selected. $40 \mu \mathrm{g}$ E and F np were weighed per well. F np contains $2.5 \mathrm{ng}$ of TGF-B1 at $40 \mu \mathrm{g}$. HaCaT cells and fibroblast cells-NIH 3 T3 were seeded in six-well plates (TPP, Switzerland) in a density of $5 \times 10^{5}$ cells/well in a growth medium. Cells were incubated until they had reached $70 \%-80 \%$ density. Then a scratch was made through each well using a sterile $200 \mu$ l pipet tip. Cells were washed twice with PBS (pH 7.4) and the medium was changed. Selected formulations and a positive control TGF- $\beta 1$ were added to the medium. At the time of the first scratch on the cells and at the $24^{\text {th }}$ and $48^{\text {th }}$ hours, the images were taken using an inverted microscope with (Olympus CKX 41 Japan) equipped with Olympus IX2 SLP phase contrast slider camera system. Cells were kept at $37^{\circ} \mathrm{C}, 5 \% \mathrm{CO}_{2}$ throughout the entire repair procedure. The experiments were repeated twice [19].

\subsection{Statistical analysis}

All results were expressed as means \pm standard deviation. The statistical analysis was performed using one-way analysis of variance (ANOVA) followed by Newman-Keuls multiple comparisons test. Differences between the groups were considered to be significant when $p<0.05$.

Acknowledgements: This study was supported by the Commission of Marmara University Scientific Research Project BAPKO (SAG-C-DRP-090217-0042).

Author contributions: Concept - A.Ç.S., A.D.S.; Design - A.Ç.S., A.D.S.; Supervision - A.Ç.S., A.D.S.; Resource - A.Ç.S., A.D.S., T.U.; Materials - A.Ç.S., A.D.S., T.U.; Data Collection and/or Processing - A.Ç.S., S.Ş.; Analysis and/or Interpretation - A.Ç.S., S.Ş.; Cyctotoxity - A.Ç.S.; Literature Search - A.Ç.S.; Writing - A.Ç.S.; Critical Reviews- A.Ç.S., S.Ş., T.U., A.D.S.

Conflict of interest statement: The authors declare no conflict of interest.

Ethics committee approval: Animal experiments were approved by the ethical committee of Marmara University Animal Experiments Local Ethics Committee (Protocol No: 46.2018.mar, 07.05.2018).

\section{REFERENCES}

[1] Hardwicke J, Schmaljohann D, Boyce D, Thomas D. Epidermal growth factor therapy and wound healing - past, present and future perspectives. The Surgeon. 2008; 6(3): 172-177. [CrossRef]

[2] Martin P. Wound healing--aiming for perfect skin regeneration. Science. 1997; 276 (5309): 75-81. [CrossRef]

[3] Demidova-Rice TN, Hamblin MR, Herman IM. Acute and impaired wound healing: pathophysiology and current methods for drug delivery, part 1: normal and chronic wounds: biology, causes, and approaches to care. Adv Skin Wound Care. 2012; 25(7): 304-314. [CrossRef]

[4] Chereddy KK, Lopes A, Koussoroplis S, Payen V, Moia C, Zhu H, et al. Combined effects of PLGA and vascular endothelial growth factor promote the healing of non-diabetic and diabetic wounds. Nanomedicine. 2015; 11(8): 19751984. [CrossRef]

[5] Chereddy KK, Vandermeulen G, Preat V. PLGA based drug delivery systems: Promising carriers for wound healing activity. Wound Repair Regen. 2016; 24(2): 223-236. [CrossRef] 
[6] Puolakkainen PA, Twardzik DR, Ranchalis JE, Pankey SC, Reed MJ, Gombotz WR. The enhancement in wound healing by transforming growth factor- $\beta 1$ (TGF- $\beta 1$ ) depends on the topical delivery system. J Surg Res.1995; $58(3)$ : 321-329. [CrossRef]

[7] Le M, Naridze R, Morrison J, Biggs LC, Rhea L, Schutte BC, et al. Transforming growth factor Beta 3 is required for excisional wound repair in vivo. PloS one. 2012; 7(10): e48040. [CrossRef]

[8] O'Kane S, Ferguson MW. Transforming growth factor $\beta$ s and wound healing. Int J Biochem Cell Biol. 1997; $29(1)$ : 6378. [CrossRef]

[9] Beanes SR, Dang C, Soo C, Ting K. Skin repair and scar formation: the central role of TGF-beta. Expert Rev Mol Med. 2003; 5(8): 1-22. [CrossRef]

[10] Gainza G, Villullas S, Pedraz JL, Hernandez RM, Igartua M. Advances in drug delivery systems (DDSs) to release growth factors for wound healing and skin regeneration. Nanomedicine. 2015; 11(6): 1551-1573. [CrossRef]

[11] Derman S, Kizilbey K, Akdeste Z. Polimeric Nanoparticles. Sigma Journal of Engineering and Natural Sciences. 2013; 31: 109-122.

[12] Dai C, Wang B, Zhao H. Microencapsulation peptide and protein drugs delivery system. Colloids Surf B Biointerfaces. 2005; 41(2-3): 117-120. [CrossRef]

[13] Jaklenec A, Hinckfuss A, Bilgen B, Ciombor DM, Aaron R, Mathiowitz E. Sequential release of bioactive IGF-I and TGF-beta 1 from PLGA microsphere-based scaffolds. Biomaterials. 2008; 29(10): 1518-1525. [CrossRef]

[14] Nie L, Zhang G, Hou R, Xu H, Li Y, Fu J. Controllable promotion of chondrocyte adhesion and growth on PVA hydrogels by controlled release of TGF- $\beta 1$ from porous PLGA microspheres. Colloids Surf B Biointerfaces. 2015; 125: 51-57. [CrossRef]

[15] Sun SB, Liu P, Shao FM, Miao QL. Formulation and evaluation of PLGA nanoparticles loaded capecitabine for prostate cancer. Int J Clin Exp Med. 2015; 8(10): 19670-19681.

[16] Sezer AD, Cevher E, Hatipoğlu F, Oğurtan Z, Baş AL, Akbuğa J. The use of fucosphere in the treatment of dermal burns in rabbits. Eur J Pharm Biopharm. 2008; 69(1): 189-198. [CrossRef]

[17] Kockisch S, Rees GD, Young SA, Tsibouklis J, Smart JD. Polymeric Microspheres for Drug Delivery to the Oral Cavity: An In Vitro Evaluation of Mucoadhesive Potential. J Pharm Sci. 2003; 92(8): 1614-1623. [CrossRef]

[18] Erdem-Çakmak F, Özbaş-Turan S, Şalva E, Akbuğa J. Comparison of VEGF gene silencing efficiencies of chitosan and protamine complexes containing shRNA. Cell Biol Int. 2014; 38(11): 1260-1270. [CrossRef]

[19] Wolf NB, Küchler S, Radowski MR, Blaschke T, Kramer KD, Weindl G, et al. Influences of opioids and nanoparticles on in vitro wound healing models. Eur J Pharm Biopharm. 2009; 73(1): 34-42. [CrossRef]

[20] Silva AL, Soema PC, Slütter B, Ossendorp F, Jiskoot W. PLGA particulate delivery systems for subunit vaccines: Linking particle properties to immunogenicity. Hum Vaccin Immunother. 2016; 12(4): 1056-1069. [CrossRef]

[21] Mainardes RM, Evangelista RC. PLGA nanoparticles containing praziquantel: effect of formulation variables on size distribution. Int J Pharm. 2005; 290(1-2): 137-144. [CrossRef]

[22] Chaisri W, Hennink WE, Okonogi S. Preparation and characterization of cephalexin loaded PLGA microspheres. Curr Drug Deliv. 2009; 6(1): 69-75. [CrossRef]

[23] Kwon H-Y, Lee J-Y, Choi S-W, Jang Y, Kim J-H. Preparation of PLGA nanoparticles containing estrogen by emulsification-diffusion method. Colloids and Surfaces A: Physicochemical and Engineering Aspects. 2001; 182(1-3): 123-130. [CrossRef]

[24] Xu B, Mensah RA, Kirton SB, Cook MT, Styliari ID, Hutter V, et al. Optimising poly(lactic-co-glycolic acid) microparticle fabrication using a Taguchi orthogonal array design-of-experiment approach. Plos One. 2019; 14(9): e0222858. [CrossRef]

[25] Vaidya PK. Mater Thesis. Controlled Delivery of TGF-\$1 from PLGA Nanoparticles. Department of Biomedical Engineering, Cleveland State University, Ohio, USA, 2012.

[26] Jaklenec A, Wan E, Murray ME, Mathiowitz E. Novel scaffolds fabricated from protein-loaded microspheres for tissue engineering. Biomaterials. 2008; 29(2): 185-192. [CrossRef]

[27] Lu L, Stamatas GN, Mikos AG. Controlled release of transforming growth factor ?1 from biodegradable polymer microparticles. J Biomed Mater Res. 2000; 50(3): 440-451. [CrossRef]

[28] Jhunjhunwala S, Balmert SC, Raimondi G, Dons E, Nichols EE, Thomson AW, et al. Controlled release formulations of IL-2, TGF- $\beta 1$ and rapamycin for the induction of regulatory T cells. J Control Release. 2012; 159(1): 78-84. [CrossRef] 
[29] Javadzadeh Y, Ahadi F, Davaran S, Mohammadi G, Sabzevari A, Adibkia K. Preparation and physicochemical characterization of naproxen-PLGA nanoparticles. Colloids Surf B Biointerfaces. 2010; 81(2): 498-502. [CrossRef]

[30] Yang Z, Wang L, Tian L, Zhang X, Huang G. Tadalafil-loaded PLGA microspheres for pulmonary administration: preparation and evaluation. Braz J Pharm Sci. 2019; 55: e17536. [CrossRef]

[31] Son S, Lee WR, Joung YK, Kwon MH, Kim YS, Park KD. Optimized stability retention of a monoclonal antibody in the PLGA nanoparticles. Int J Pharm. 2009; 368(1-2): 178-185. [CrossRef]

This is an open access article which is publicly available on our journal's website under Institutional Repository at http://dspace.marmara.edu.tr. 